\title{
Spatial Distribution of Exhalation Droplets in the Bus in Different Seasons
}

Aerosol and Air Quality Research

Special Issue:

Special Issue on COVID-19 Aerosol Drivers, Impacts and Mitigation $(\mathrm{XVI})$

\author{
Wenzhu Duan ${ }^{1,2}$, Dan $\mathrm{Mei}^{1,2^{*}}$, Jiaqian $\mathrm{Li}^{1}$, Zihan Liu${ }^{1}$, Mengfan Jia ${ }^{1}$, \\ Shanshan $\mathrm{Hou}^{2}$ \\ ${ }^{1}$ Hubei Key Laboratory for Efficient Utilization and Agglomeration of Metallurgic Mineral \\ Resources, Wuhan University of Science and Technology, Wuhan 430081, China \\ ${ }^{2}$ Hubei Provincial Industrial Safety Engineering Technology Research Center, Wuhan University \\ of Science and Technology, Wuhan 430081, China
}

\section{ABSTRACT}

In closed buses, the spread of droplets with viruses/bacteria may cause the spread of respiratory infectious diseases. Discrete phase modeling is used to simulate the diffusion characteristics and concentration distribution of droplets at different temperatures and different exhalation positions by ANSYS FLUENT software. The integral concentration of droplets at different locations can be quantified, which leads to identification of low-risk areas and high-risk areas in the bus.

Results show that a higher outdoor temperature leads to lower droplets' diffusion speed and longer time until the droplets reach the driver. In addition, based on the integral concentration of droplets at the seats, regardless of whether a passenger exhales droplets in the front row of the bus, the position of the rear door or the last row of the bus, the seats in the last row of the bus away from the door belong to the low-risk area. In contrast, the seats near the door and the middle seat in the bus are higher risk areas. Consequently, this study proposed sitting on a seat in the low-risk area as a means to reduce the risk of passengers. Moreover, safety protection facilities around the driver should be modified to improve the isolation of the upper area of the driver's location, so as to effectively prevent the droplet diffusion towards the driver, thereby effectively reducing the driver's risk of infection.

Keywords: Expiratory droplets, Droplet diffusion, Concentration distribution, Outdoor temperature

\section{INTRODUCTION}

Revised: April 7,2

Accepted: April 14, 2021

${ }^{*}$ Corresponding Author: meidan@wust.edu.cn

\section{Publisher:}

Taiwan Association for Aerosol Research

ISSN: $1680-8584$ print

ISSN: 2071-1409 online

Copyright: The Author(s). This is an open access article distributed under the terms of the Creative Commons Attribution License (CC BY 4.0), which permits unrestricted use, distribution, and reproduction in any medium, provided the original author and source are cited.
In recent years, airborne diseases such as severe acute respiratory syndrome (SARS), avian and swine flu (H1N1), and new coronavirus pneumonia (COVID-19) have significantly increased, which may cause serious public health and financial burdens on society (WHO, 2020). Currently, COVID-19 already has spread globally. As of March 30, 2021, the cumulative number of patients diagnosed with COVID-19 was more than 128 million, and the cumulative death toll exceeded 2.79 million (National Health Commission of the People's Republic of China, 2020). At this stage, droplet transmission has been proven to be a dominant way of respiratory disease transmission among people, which can spread a variety of infectious diseases such as influenza and SARS-CoV-2 (Stilianakis and Drossinos, 2010; Vuorinena et al., 2020; Xu et al., 2020). COVID-19 is primarily transmitted human-to-human via respiratory aerosols (Rahman et al., 2020). Compared to other transmission routes, aerosols are more capable of carrying viruses and can spread farther in the environment (Xie et al., 2007; Lindsley et al., 2010). In addition, studies have found that air circulation is poor in a confined space, which causes droplets to remain suspended in the indoor environment for longer, making people exposed to this environment more likely to be exposed to and infected with the virus (Bartzis et al., 2015; Zhou et al., 2018).

Buses, currently the most popular means of transportation, have introduced great convenience to people's travel. However, buses pose the obvious characteristics of large flow of people in and 
out, high density of people in a confined space, and poor air circulation. More importantly, the bus is not only a social service place, but also a public carrier of social action, with high mobility of people. The above characteristics will increase the risk of various infectious diseases spreading among passengers through droplets. It has been reported that the spread of COVID-19 in airconditioned, airtight compartments can reach up to $4.5 \mathrm{~m}$, and the virus can float in the air for at least 30 minutes, eventually causing the infection of people in these compartments (Yang et al., 2020). Thus, it is essential to study the transmission law of the virus carrier (oral droplets) in a confined bus space.

Since the outbreak of SARS in 2003, researchers on a national and international level have carried out experimental and numerical simulation studies on indoor ventilation and air transmission of residential buildings (Mao and Gao, 2015), wards (Berlanga et al., 2018), isolation rooms (Yang et al., 2015), hospitals (Qian et al., 2010), general indoor environment (Zhao and Wu, 2005; Yang et al., 2014; Cao et al., 2015; Zhang et al., 2019), passenger cars (Yang et al., 2020) and highspeed railway cabins (Zhang and Li, 2012). Researchers have also studied the transfer characteristics and influencing factors of droplets in different scenes (Li et al., 2014; Berlanga et al., 2017; Zhou et al., 2017; Ji et al., 2018; Yan et al., 2019). Zhu et al. (2006) investigated the transmission characteristics of droplets from coughing in a quiet indoor environment. They found that droplets overweighting $6.7 \mathrm{mg}$ were discharged at a speed of $22 \mathrm{~m} \mathrm{~s}^{-1}$ and their moving distance exceeded $2 \mathrm{~m}$ in each cough process. The study revealed that the transmission characteristics of droplets produced by coughing varied with the diameter of the droplet. The effect of gravity or inertial force on droplets with a diameter of $\leq 30 \mu \mathrm{m}$ was very small and could be basically ignored, whereas droplets of size ranging from $50 \mu \mathrm{m}$ to $200 \mu \mathrm{m}$ were significantly affected by gravity. For droplet of with a diameter of $\geq 300 \mu \mathrm{m}$, the influence of inertial was dominant compared to and the influence of gravity, so droplets did not descend significantly, and nearly $100 \%$ of droplets impacted on the neck of the opposite person. In addition, this study showed that the spatial relationship between the air conditioner and the person exhaling droplets had also an important influence on the transmission of droplets.

The droplets produced by breathing, talking, coughing and other behaviors are similar in size (Gralton et al., 2011). The diameters of droplets produced by breathing, talking, and coughing range from $0.1 \mu \mathrm{m}$ to $10 \mu \mathrm{m}, 0.05 \mu \mathrm{m}$ to $10 \mu \mathrm{m}$, and $0.05 \mu \mathrm{m}$ to $5 \mu \mathrm{m}$, respectively. However, the difference in the way droplets generated will affect their transmission and distribution indoors. Zhao et al. (2005) studied the indoor droplet transmission and distribution influenced by droplet generation and various breathing activities, including normal breathing, sneezing or coughing. It is found that humans produce fewer droplets during normal breathing, with shorter transmission distance than sneezing or coughing, while the number of droplets produced when a person coughs or sneezes is large, and the transmission distance can exceed $3 \mathrm{~m}$. Liu et al. (2017) found that the size of the droplet nuclei was larger in humid air than in dry air, and the travel distance and the final destinations of small droplets were related to initial size, residue size and humidity. Medium-sized droplets $(60 \mu \mathrm{m})$ were affected by humidity on a higher degree, while large droplets quickly precipitated out of the jet stream and were less affected by humidity. Several other studies considered the influence of ventilation methods and other factors on droplet diffusion (Zhao et al., 2004; Mui et al., 2009; Chen and Zhao, 2010; He et al., 2011; Licina et al., 2015; Ai et al., 2019).

Wang et al. (2020) researched the spread of COVID-19. The research team collected the number of confirmed cases of COVID-19 in China and 24 other countries from January 20, 2020 to February 4, 2020. At the same time, the average, maximum and minimum temperatures in January were calculated, and a restricted cubic function and a generalized linear mixed model were utilized to identify the best fit between the daily logarithmic value $(\operatorname{lgN})$ and temperature. Data fitting showed that the $\operatorname{lgN}$ rose as the average temperature went up to a peak of $8.72^{\circ} \mathrm{C}$ and then slowly declined. The results of the study have shown that temperature can significantly change the spread of COVID-19 to a certain extent, and there might be an optimal temperature for the viral transmission, partially explaining the initial outbreak of the virus in Wuhan. Furthermore, some scholars have found that the temperature significantly changes COVID-19 transmission in (sub) tropical cities of Brazil (Prata et al., 2020). This study found a negative linear relationship between temperatures and daily cumulative confirmed COVID-19 cases in the range from $16.8^{\circ} \mathrm{C}$ to $27.4^{\circ} \mathrm{C}$. Each $1^{\circ} \mathrm{C}$ rise of temperature was associated with a $-4.8951 \%$ decrease in 
the number of daily cumulative confirmed cases of COVID-19. Given this evidence, the influence of temperature on droplet propagation is considered in this study.

Droplets are discharged into indoor environment through patient's breathing, talking, coughing, or other activities involving use of nose or mouth. If the droplets are directly inhaled or settled on people close to the patient, it will cause close-range droplet transmission infection, with people who are closer to the patient being at higher risk of contracting infectious diseases (Liu et al., 2016; Chen et al., 2020). However, if the virus carried by the droplets is still active, it will cause long-distance droplet transmission infection, and people who are far from the patient will also be at risk of infection (Zhu et al., 2012; Yang et al., 2020). Due to spatial variability in the spreading of an airborne pathogen in an indoor environment, risk levels may very locally. This may apply to a bus as well.

To sum up, most of the researches examples presented so far focus on the transmission and diffusion of droplets in the indoor environment, and aim to study the influence of ventilation methods, relative humidity and droplet size on droplet diffusion. Diffusion of droplets in a bus is not yet thoroughly researched, with only a few examples available. The bus is selected as the research object in this study, owing to it being considered an indoor environment with poor air circulation and a public carrier of social action, handling a large flow and high density and high mobility of people (National Bureau of Statistics, 2020). This paper also aims to study the influence of the outdoor temperature and the droplet exhalation position on the diffusion and distribution of droplets inside the environment of a closed bus. More importantly, the spatial differences are quantified by the integral concentration of droplets of different positions, providing suggestions for the reduction of the risk of passengers contracting an infectious disease in a closed bus.

\section{METHODOLOGY}

\subsection{Description of the Geometry and Simulation Cases}

In daily life, buses will regularly stop at the station, and the temporal and spatial distributions of droplets in the bus are affected by passenger movement and the opening and closing of the doors. However, the moving state is the normal state in the process of the bus being driven by the driver. At this time, the door is closed and the passengers remain still, which will not affect the temporal and spatial distribution of droplets in the bus. Therefore, the bus in the moving state is taken as the research object. A bus, with dimensions of $10 \mathrm{~m} \times 2.3 \mathrm{~m} \times 2.5 \mathrm{~m}(\mathrm{~L} \times \mathrm{W} \times \mathrm{H})$ based on the commonly used bus model of ZK was adopted to study the influence of the outdoor temperature and the droplet exhalation position on the diffusion and distribution of droplets in the bus. The detailed descriptions of the enclosed bus are summarized in Fig. 1 and Table 1. The return air outlet was set in the middle of the roof with a size of $2.4 \mathrm{~m} \times 0.4 \mathrm{~m}(\mathrm{~L} \times \mathrm{W})$ and the air

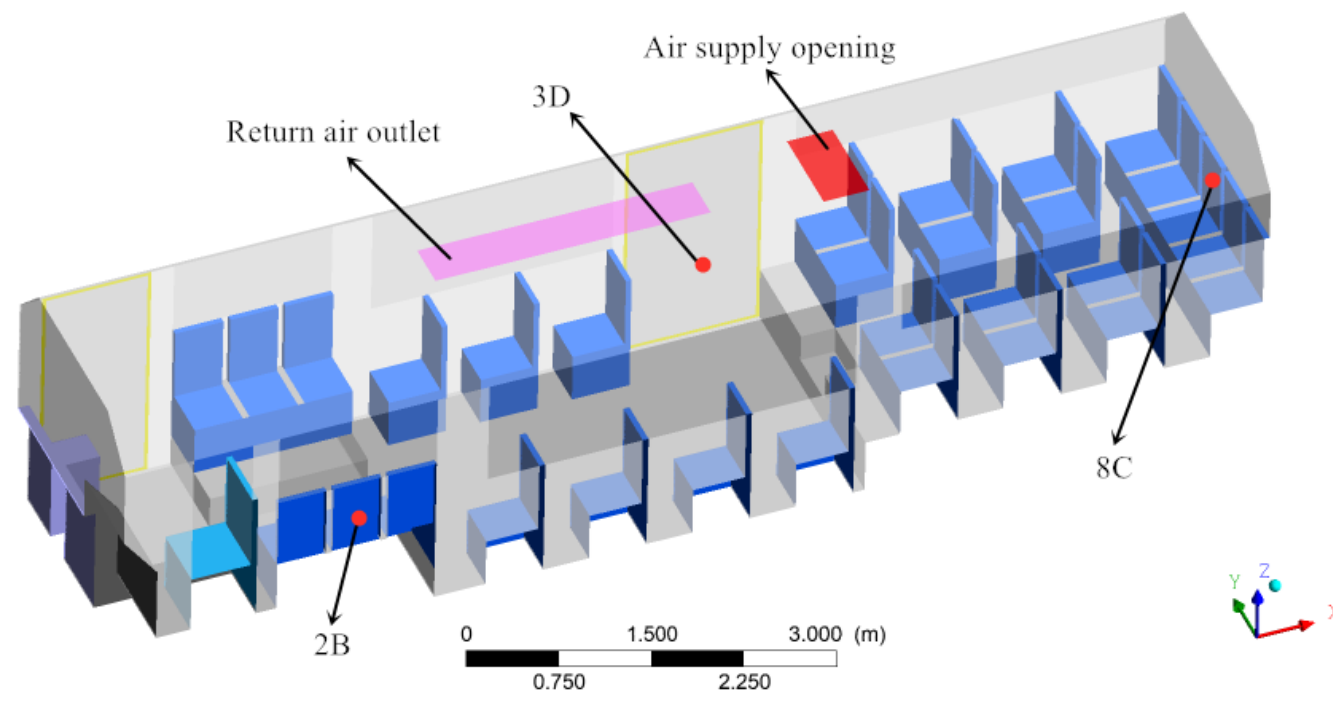

Fig. 1. Computational domain model in the bus. 
Table 1. Summary of CFD domain size and setup parameters of bus model.

\begin{tabular}{lllll}
\hline Name & Number & $X(\mathrm{~m})$ & $\mathrm{Y}(\mathrm{m})$ & $\mathrm{Z}(\mathrm{m})$ \\
\hline bus & 1 & 9.996 & 2.3 & 2.5 \\
passenger's seat & 24 & 0.502 & 0.42 & 0.45 \\
passenger's seat back & 24 & 0.05 & 0.42 & 0.67 \\
passenger's seat & 6 & 0.42 & 0.502 & 0.45 \\
passenger's seat back & 6 & 0.42 & 0.05 & 0.67 \\
driver's seat & 1 & 0.57 & 0.57 & 0.55 \\
driver's seat back & 1 & 0.05 & 0.57 & 0.67 \\
air supply opening & 1 & 0.4 & 0.8 & $/$ \\
return air outlet & 1 & 2.4 & 0.4 & $/$ \\
mouth & $/$ & 0.05 & 0.05 & 0.05 \\
\hline
\end{tabular}

Table 2. Parameters and setups in case studies.

\begin{tabular}{lll}
\hline Cases & Name & Purpose \\
\hline outdoor temperature & $5^{\circ} \mathrm{C}$ & investigate the diffusion and distribution of droplets in the \\
& $15^{\circ} \mathrm{C}$ & bus in different seasons \\
& $25^{\circ} \mathrm{C}$ & \\
& $35^{\circ} \mathrm{C}$ & \\
the location where the droplets are & seat $2 \mathrm{~B}$ & investigate the diffusion and distribution of droplets in the \\
exhaled & seat 3D & bus when the droplet exhalation position is different \\
& position $8 \mathrm{C}$ & \\
& position $2 \mathrm{~B} / 3 \mathrm{D} / 8 \mathrm{C}$ & \\
\hline
\end{tabular}

supply opening was set near the rear door in the middle of the roof with a size of $0.4 \mathrm{~m} \times 0.8 \mathrm{~m}$ $(\mathrm{L} \times \mathrm{W})$. Furthermore, seat selection and the movement of passengers are random. There is no possible way to determine where a passenger will sit. Hence, there is no passenger body model in the bus but only a cube is used to simulate the mouth of the passenger exhaling droplets with size of $0.05 \mathrm{~m} \times 0.05 \mathrm{~m} \times 0.05 \mathrm{~m}(\mathrm{~L} \times \mathrm{W} \times \mathrm{H})$.

Table 2 lists the simulation cases conducted to study the diffusion and distribution of droplets in the bus upon different seasons and exhalation positions. According to the geographical location of Wuhan and the average temperature of each season in Wuhan, the outdoor temperature is set to $15^{\circ} \mathrm{C}$ in spring, $35^{\circ} \mathrm{C}$ in summer, $25^{\circ} \mathrm{C}$ in autumn and $5^{\circ} \mathrm{C}$ in winter. The four exhalation positions considered are that a passenger exhales droplets in seat $2 \mathrm{~B}$, position $3 \mathrm{D}$, or seat $8 \mathrm{C}$ in the bus, and all passengers in the above three positions exhale droplets, as shown in Fig. 1.

\subsection{Mesh Generation}

In numerical simulation, the model needs to be meshed. Meshing divides the entire model into many small cells, with vertices, edges, and faces that comprise a grid. The ICEM software is a CAE pre-processing software with powerful CAD model repair capabilities, unique mesh generation technology and extensive solver support capabilities (Ansys Inc., 2018). In the simulation process, the ICEM software was used to establish model used to describe the bus. The Global Element Scale Factor was set to 2 and the Global Element Seed Size was set to 0.04 to generate an unstructured grid. Refined boundary layers were employed near the assumed passenger mouths and outlet where the velocity gradient may be greater (Fig. 2). The mesh size of the mouth was set as $0.005 \mathrm{~m}$. Similarly, the mesh size on the outlet was set as $0.03 \mathrm{~m}$. The total number of grid elements was about 1.35 million, which was determined by refining the mesh until the flow field solution was independent of the grid.

\subsection{Numerical Modeling of Airflow}

\subsubsection{Governing equation}

Fluid and temperature simulation calculation is mainly based on three governing equations, namely mass conservation equation, momentum conservation equation and energy conservation equation. 
(a)

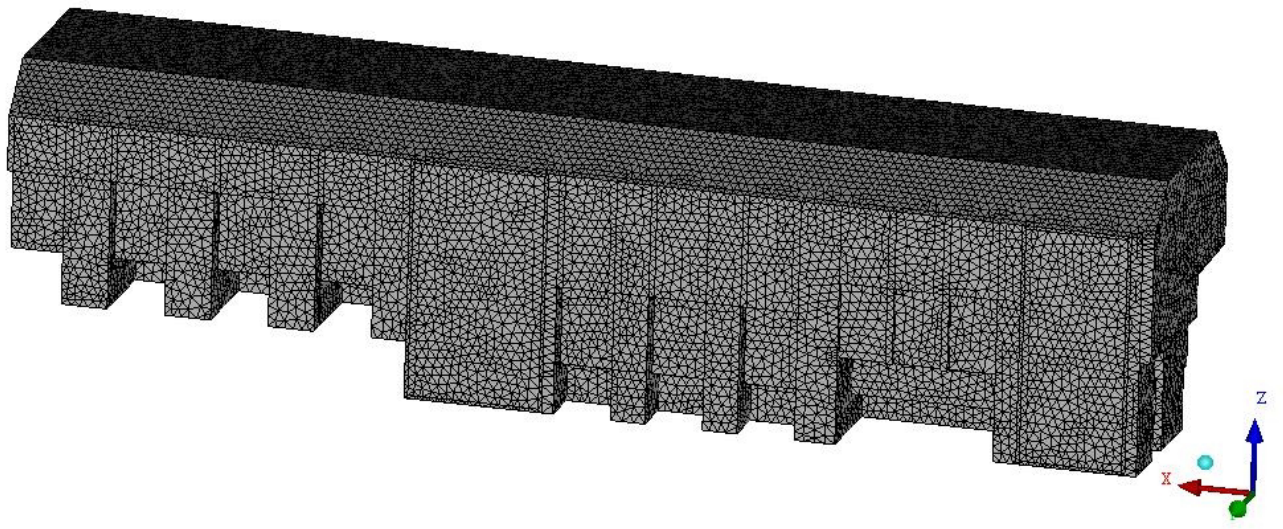

(b)
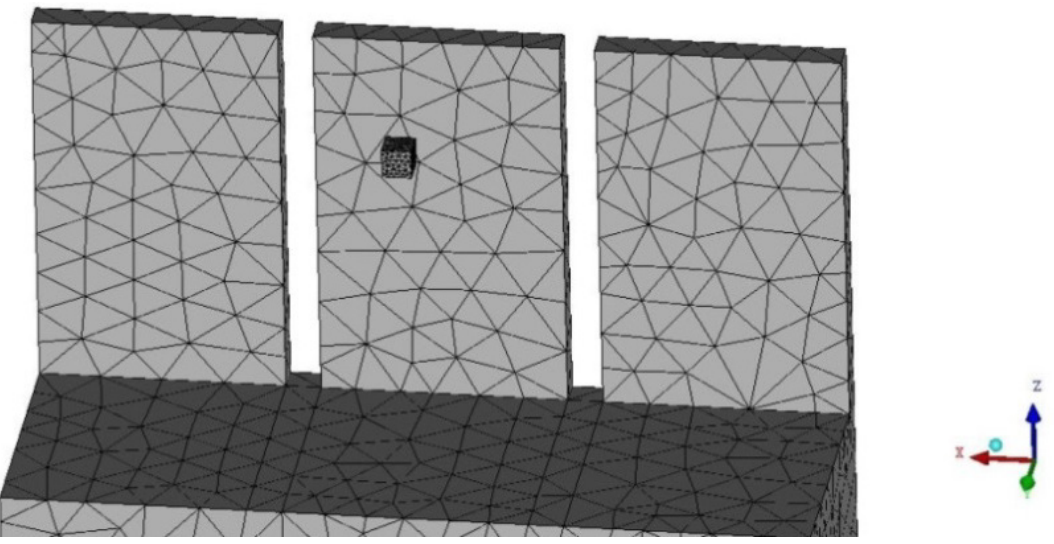

Fig. 2. The grid arrangements in the bus and around the mouth.

The continuity equation is as follows:

$\frac{\partial u}{\partial x}+\frac{\partial v}{\partial y}+\frac{\partial w}{\partial z}=0$

where $u, v, w$ are the velocity components in the $\mathrm{x}, \mathrm{y}$, and $\mathrm{z}$ directions.

According to the law of conservation of momentum, the conservation equation of momentum in the three directions of $x, y$, and $z$ in the three-dimensional space can be obtained as follows:

$$
\begin{aligned}
& \frac{\partial(\rho u)}{\partial t}+\operatorname{div}(\rho u u)=\operatorname{div}(\mu g r a d u)-\frac{\partial p}{\partial x} \\
& \frac{\partial(\rho v)}{\partial t}+\operatorname{div}(\rho v u)=\operatorname{div}(\mu g r a d v)-\frac{\partial p}{\partial y} \\
& \frac{\partial(\rho w)}{\partial t}+\operatorname{div}(\rho w \boldsymbol{u})=\operatorname{div}(\mu g r a d w)-\frac{\partial p}{\partial z}-\rho g
\end{aligned}
$$

where $p$ is the pressure on the fluid microelement, $\mu$ is the dynamic viscosity, $g$ is the gravitational acceleration.

The energy conservation equation is as follows:

$$
\frac{\partial(\rho T)}{\partial t}+\operatorname{div}(\rho \boldsymbol{u} T)=\operatorname{div}\left(\frac{k}{c_{p}} \operatorname{grad} T\right)+S_{T}
$$


where $\rho$ is the density, $T$ is the temperature, $t$ is time, $\boldsymbol{u}$ is the velocity vector, $c_{p}$ is the specific heat capacity, $k$ is the heat transfer coefficient of the fluid, and $S_{T}$ is the viscous dissipation term.

The Boussinesq model treats density as a constant value in all solved equations, except for the buoyancy term in the momentum equation:

$$
\left(\rho-\rho_{0}\right) g \approx-\rho_{0} \beta\left(T-T_{0} g\right)
$$

where $\rho_{0}$ is the (constant) density of the flow, $T_{0}$ is the operating temperature, and $\beta$ is the thermal expansion coefficient.

\subsubsection{Turbulence model}

As is well-known, indoor airflow is considered to be turbulent. Turbulence models mainly include the standard k- $\varepsilon$ model, the RNG k- $\varepsilon$ model and the realizable k- $\varepsilon$ model (Ansys Inc., 2018). Compared with the standard k- $\varepsilon$ model and the RNG k- $\varepsilon$ model, the realizable $k-\varepsilon$ model consists of a new model dissipation rate equation and a new realizable eddy viscosity formulation. In addition, the realizable k- $\varepsilon$ model implements mathematical constraints on the Reynolds stress, making the flow more aligned with the physical laws of turbulence (Shih et al., 1995). Furthermore, the realizable $k-\varepsilon$ model can accurately predict the diffusion rate of plane jets and circular jets, and it can be applicable to various types of flow simulation with good convergence and accuracy (Lateb et al., 2013). Therefore, the Realizable k- $\varepsilon$ model is utilized to simulate the flow field in the bus. In the Realizable $k-\varepsilon$ model, the transport equations for $k$ and $\varepsilon$ are as follows:

$$
\frac{\partial}{\partial t}(\rho k)+\frac{\partial}{\partial x_{j}}\left(\rho k u_{j}\right)=\frac{\partial}{\partial x_{j}}\left[\left(\mu+\frac{\mu_{t}}{\sigma_{k}}\right) \frac{\partial k}{\partial x_{j}}\right]+G_{k}+G_{b}-\rho \varepsilon-Y_{M}+S_{k}
$$

and

$$
\frac{\partial}{\partial t}(\rho \varepsilon)+\frac{\partial}{\partial x_{j}}\left(\rho \varepsilon u_{j}\right)=\frac{\partial}{\partial x_{j}}\left[\left(\mu+\frac{\mu_{t}}{\sigma_{\varepsilon}}\right) \frac{\partial \varepsilon}{\partial x_{j}}\right]+\rho C_{1} S \varepsilon-\rho C_{2} \frac{\varepsilon^{2}}{k+\sqrt{v \varepsilon}}+C_{1 \varepsilon} \frac{\varepsilon}{k} C_{3 \varepsilon} G_{b}+S_{\varepsilon}
$$

where $C_{1}=\max \left[0.43, \frac{\eta}{\eta+5}\right], \eta=S \frac{k}{\varepsilon}, S=\sqrt{2 S_{i j} S_{i j}}$.

In these equations, $G_{k}$ represents the generation of turbulence kinetic energy due to the mean velocity gradients. $G_{b}$ is the generation of turbulence kinetic energy due to buoyancy. $Y_{M}$ represents the contribution of the fluctuating dilatation in compressible turbulence to the overall dissipation rate. $C_{2}$ and $C_{1_{\varepsilon}}$ are constants. $\sigma_{k}$ and $\sigma_{\varepsilon}$ are the turbulent prandtl numbers for $\mathrm{k}$ and $\varepsilon$, respectively. $S_{k}$ and $S_{\varepsilon}$ are user-defined source terms.

The SIMPLE algorithm is a numerical method mainly used to solve incompressible flow fields. Using the "guess-correction" process it calculates the pressure field on the basis of staggered grids, in order to achieve the purpose of solving the momentum equation (Patanker and Spalding, 1972). In this work, the SIMPLE algorithm was used to decouple pressure and speed. In addition, the second-order upwind style was used to discretize the convection and diffusion convection terms in the governing equations.

\subsubsection{Discrete phase modeling}

Lagrangian method was used to track droplets. The force balance for a droplet is given in a Lagrangian reference frame, which contains inertia, stokes drag and gravitational force. And the form of the droplet force balance equation in the Cartesian coordinate system ( $x$ direction) is as follows:

$$
\frac{d u_{p}}{d t}=F_{D}\left(u-u_{p}\right)+F_{g}
$$


where $u_{p}$ is the droplet velocity, $u$ is the fluid phase velocity, $F_{g}$ is the gravitational force, and $F_{D}(u$ $\left.-u_{p}\right)$ is the Stokes drag force.

$F_{g}=\frac{g_{x}\left(\rho_{p}-\rho\right)}{\rho_{p}}$

$F_{D}=\frac{18 \mu}{\rho_{P} d_{p}^{2} C_{c}}$

where $\rho_{p}$ and $\rho$ are the density of droplet and air, respectively, $\mu$ is the molecular velocity of air, $d_{p}$ is the droplet diameter, and $C_{c}$ is the Cunningham correction to Stokes drag law which is defined as follows:

$C_{C}=1+\frac{2 \lambda}{d_{P}}\left(1.257+0.4 e^{-\left(\frac{1.1 d_{p}}{2 \lambda}\right)}\right)$

where $\lambda$ is the molecular mean free path of air.

In addition, in order to simplify the calculation, this article also used the following assumptions:

(1) the effect of droplets on turbulence was negligible;

(2) the heat transfer between air and droplets was ignored;

(3) the droplets were "trapped" by the wall surface as they moved to the wall surface;

(4) there was no collision or aggregation between the droplets, and the droplet size didn't change;

(5) all droplets were spherical smooth droplets.

\subsection{Boundary Conditions}

It is well established that the diffusion of droplets is largely determined by gravity (Zhu et al., 2006; Xie et al., 2007; Ji et al., 2018; Mcgrath et al., 2019). Large droplets above $20 \mu \mathrm{m}$ settle quickly, while $1 \mu \mathrm{m}$ droplets have a long suspension time in the air (Liu et al., 2016; Liu et al., 2017). Researches have shown that millions of droplets can be produced when a person coughs, with their size varying between 10 and $100 \mu \mathrm{m}$, but large-sized droplets will quickly split into $1 \mu \mathrm{m}$ sized droplets (Zhao et al., 2003). The time that the droplets remain in large size is very short and difficult to determine, and also large droplets settle quickly. Hence the large-sized droplets can be ignored, and all droplets mentioned in this work are droplets with a small droplet size. Specifically, the droplet size was set to $1 \mu \mathrm{m}$ and the density to $600 \mathrm{~kg} \mathrm{~m}^{-3}$ (Zhao et al., 2005). The speed of coughing was set to $20 \mathrm{~m} \mathrm{~s}^{-1}$ and the duration of coughing was $0.5 \mathrm{~s}$ (Zhao et al., 2005). All boundary conditions for the airflow are summarized in Table 3.

Table 3. Boundary conditions.

\begin{tabular}{ll}
\hline Boundary name & Boundary conditions \\
\hline air supply opening & velocity-inlet; velocity is $0.6 \mathrm{~m} \mathrm{~s}^{-1}$, temperature equals to $293 \mathrm{~K}$ \\
mouth & velocity-inlet; velocity is $20 \mathrm{~m} \mathrm{~s}^{-1}$, temperature equals to $310 \mathrm{~K}$ \\
outlet & pressure-outlet; $0 \mathrm{~Pa}$ \\
return air outlet & pressure-outlet; $-10 \mathrm{~Pa}$ \\
mouth5 & wall; heat transfer coefficient $=0 \mathrm{~W} \mathrm{~m}^{-2} \mathrm{~K}^{-1}$; standard wall function, no slip wall \\
back; front; right; top & wall; heat transfer coefficient $=1.3 \mathrm{~W} \mathrm{~m}^{-2} \mathrm{~K}^{-1}$; standard wall function, no slip wall \\
driver window; window & wall; heat transfer coefficient $=3 \mathrm{~W} \mathrm{~m}^{-2} \mathrm{~K}^{-1}$; standard wall function, no slip wall \\
door1; door2; windshield & wall; heat transfer coefficient $=5 \mathrm{~W} \mathrm{~m}^{-2} \mathrm{~K}^{-1}$; standard wall function, no slip wall \\
coin box; console; ground; driver's seat & wall; heat flux $=0$; standard wall function, no slip wall \\
$\quad$ and passengers' seats & \\
last row of seats & wall; heat flux $=20 \mathrm{~W} \mathrm{~m}^{-2}$; standard wall function, no slip wall \\
\hline
\end{tabular}




\subsection{Integral Concentration of Droplets}

In order to explore the spatial difference in the bus, it is necessary to determine the concentration of droplets in different seats. Accordingly, the droplet concentration at different seats was mainly obtained by integrating the droplet concentration in the area. And the integral concentration of droplets in the area is determined by Eq. (13).

$Q=\int_{a}^{b} C_{A}(x) d x$

where $Q$ is the integral concentration of droplets at the seat, $C_{A}(x)$ refers to the droplet concentration of the surface at different positions in the area, $a$ and $b$ are the initial and final positions of the surface respectively.

\subsection{Validation of Numerical Simulations}

In this study, ANSYS FLUENT (Ansys Inc., 2018) was applied for verification and subsequent numerical case studies. As shown in Fig. 3, the numerical simulation results obtained in this study were compared with simulation data of Zhao et al. (2005) to verify the scientific accuracy and applicability of the proposed calculation model.

During the verification process, the supply air velocity and the grille inlet velocity were set to $1 \mathrm{~m} \mathrm{~s}^{-1}$ and $20 \mathrm{~m} \mathrm{~s}^{-1}$ respectively. The outlet was set as the pressure outlet boundary, and the building wall and ground were set as non-slip wall. It can be seen from Table 4 that the relative error between the simulation results obtained herein and those of Zhao et al. (2005) is less than 5\%, indicating that the numerical calculation model used in this study is reliable and proving its scientific accuracy and applicability. The reason for the observed error may be that the simulated geometry used for this work is a simplification of the geometry used by Zhao et al. (2005). The uncertainty of the outlet boundary, as well as the number and quality of the grids can also result to errors.
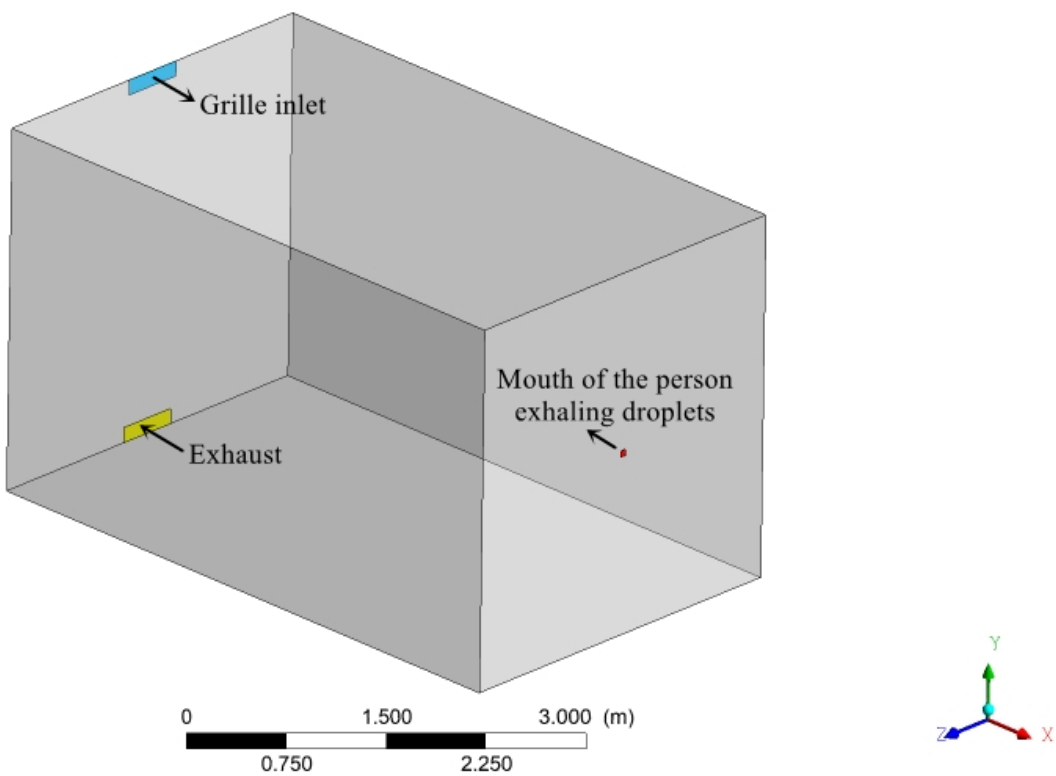

Fig. 3. Description of a room in CFD validation case referring to Zhao et al. (2005).

Table 4. The comparison of droplet concentration.

\begin{tabular}{llll}
\hline Position & Current simulation $\left(\mu \mathrm{g} \mathrm{kg}^{-1}\right)$ & Zhao et al. $(2005)\left(\mu \mathrm{g} \mathrm{kg}^{-1}\right)$ & Relative error \\
\hline $\mathrm{X}=2.5 \mathrm{~m}$ & 0.238 & 0.25 & $4.8 \%$ \\
$\mathrm{X}=3.0 \mathrm{~m}$ & 0.205 & 0.20 & $2.5 \%$ \\
$\mathrm{X}=3.5 \mathrm{~m}$ & 0.258 & 0.25 & $3.2 \%$ \\
$\mathrm{X}=4.0 \mathrm{~m}$ & 0.115 & 0.12 & $4.2 \%$ \\
\hline
\end{tabular}




\section{RESULTS AND DISCUSSION}

\subsection{Effect of Seasons on Droplet Diffusion Characteristic}

\subsubsection{Droplet diffusion in different seasons}

It is known that when people board the bus, they mainly gather at the back door of the bus. In order to better analyze the diffusion and distribution of droplets during different seasons, the exhalation position of droplets was set to commence from the position 3D, as shown in Fig. 4. The central section of the mouth of the passenger exhaling droplets $(Y=1.905 \mathrm{~m})$ is used as the main analysis section, and the velocity vector and temperature distribution of the section, both obtained by numerical calculation, are presented in Figs. 5 and 6 respectively.

It can be seen from Fig. 5 that the action of coughing produces a strong airflow towards the front of the bus, and an upward airflow is also produced at the return air outlet due to the pressure difference. Moreover, it was revealed that due to the gap introduced by the presence of a door, the air velocity at the front door and the rear door of the bus is higher than in other positions.

As can be seen in Fig. 6 , during spring $\left(T=15^{\circ} \mathrm{C}\right)$ and winter $\left(T=5^{\circ} \mathrm{C}\right)$, the outside temperature is lower compared to the other two seasons. During this time, the heat dissipation from the rear engine of the bus is dominant, so the temperature of the rear section of the bus is higher than that measured at the front row. In summer $\left(T=35^{\circ} \mathrm{C}\right)$ and autumn $\left(T=25^{\circ} \mathrm{C}\right)$, the outside temperature is higher than in spring and winter. During this time, the heat transfer coefficient of the front windshield is larger than that of the bus box, which increases the heat transfer of the front section of the bus, hence leading to the temperature of the front of the bus being higher. While the heat dissipation from the rear engine makes the temperature in the rear of the bus cabin higher. Despite the higher temperature in the front and rear end of the bus, due to the low air supply temperature, the temperature in the middle of the bus is lower. This explains the trend of the temperature inside the bus, which is first decreasing and then increasing along the direction towards the rear of the bus. In addition, it is observed that the temperature gradient of the flow field near the location of the driver is small. This indicates that the droplets gradually

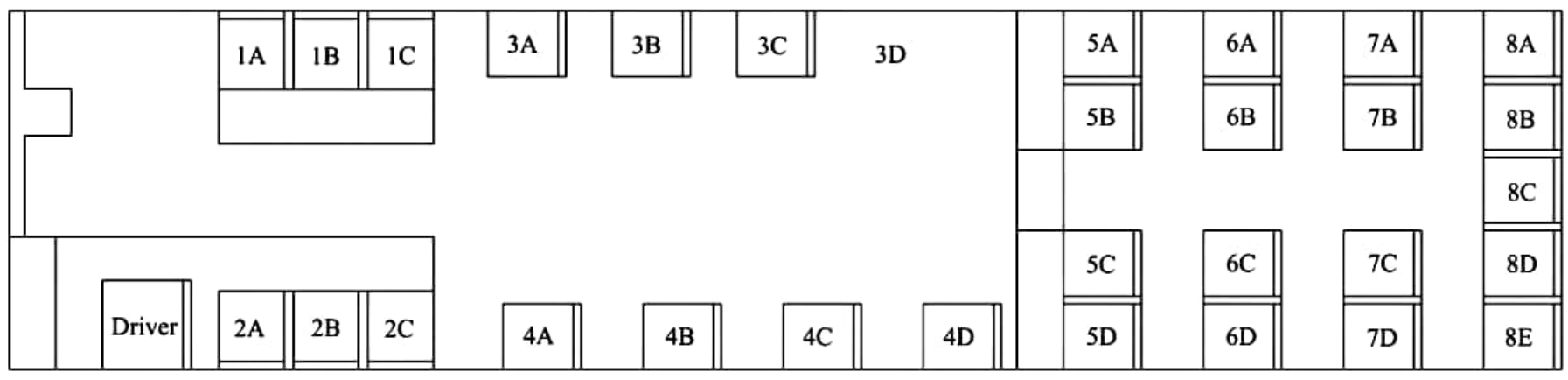

Fig. 4. The seat distribution in the bus.
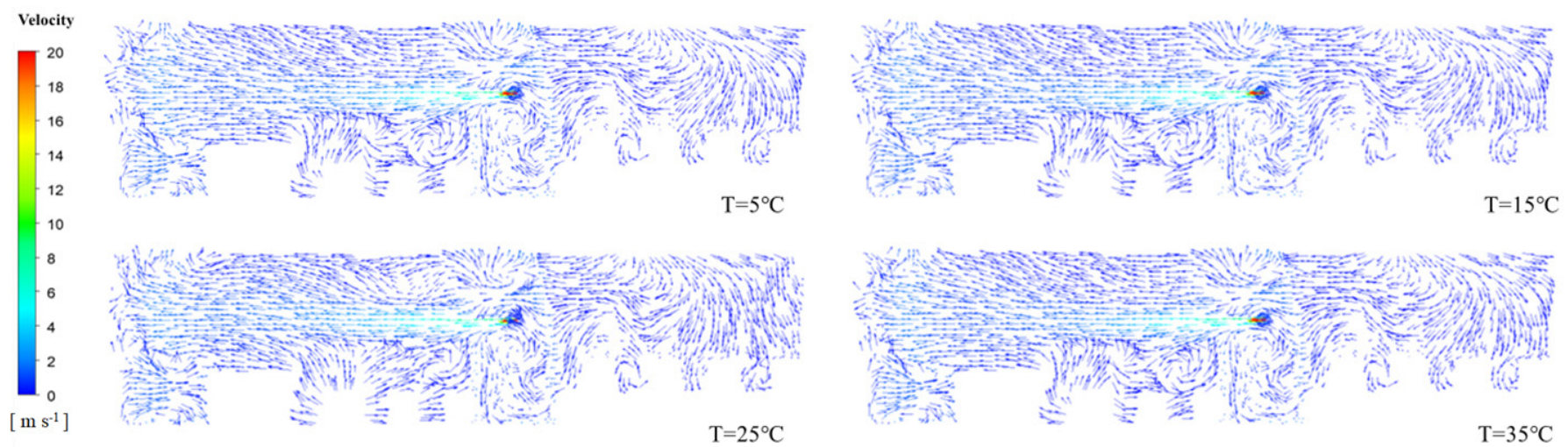

Fig. 5. The speed distribution at $Y=1.905 \mathrm{~m}$. 


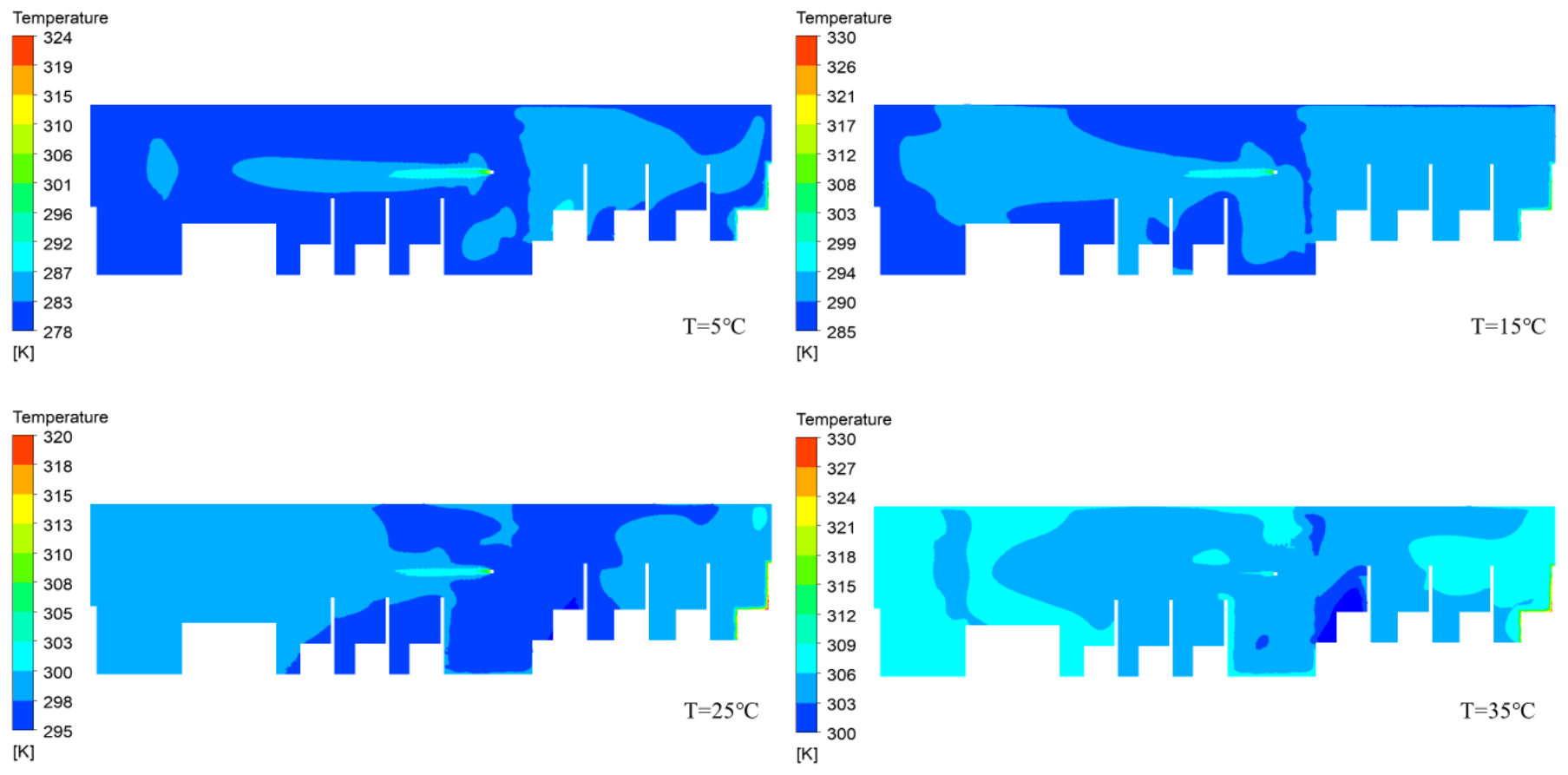

Fig. 6. The temperature distribution at $Y=1.905 \mathrm{~m}$.

diffuse to the front of the bus along the -X direction, and the diffusion range is gradually expanded, as shown in Fig. 7.

The airflow characteristics generated by the oral cough and the temperature distribution in the bus leading to the diffusion of droplets in Fig. 7, are illustrated in Figs. 5 and 6 respectively. Since the trajectory of droplets in the bus is almost the same in different seasons, Fig. 7 is used to show the diffusion process of droplets in the bus. As illustrated in Fig. 7, when the person stops coughing at $t=0.5 \mathrm{~s}$, the droplets are present in formation of a bat. Afterwards, the droplets gradually spread forward and upward, owing to the action of the airflow. At $t=2 \mathrm{~s}$, the droplets mainly gather on the upper area of the bus, forming a cylinder, before gradually spreading to the front of the bus. As time progresses, the droplets spread to the front door of the bus at $t=4 \mathrm{~s}$, and gradually move towards the location of the driver due to the airflow generated by the gap in the front door. At $t=6 \mathrm{~s}$, most of the droplets have been suspended in the front part of the bus. After that point, the droplets gradually spread backward.

When the outside temperature is different, the time and average concentration of droplets reaching the driver's location are also different, as indicated in Table 5 . When the outside temperature is low (in winter, $\mathrm{T}=5^{\circ} \mathrm{C}$ ), after the passenger has finished coughing, it takes $4 \mathrm{~s}$ for droplets to reach the location of the driver, and the average droplet concentration at the location of the driver is low, at $1.70 \times 10^{-2} \mu \mathrm{g} \mathrm{m}^{-3}$. As the temperature increases, when the outside temperature is $15^{\circ} \mathrm{C}$ (in spring), the droplets take approximately $4.5 \mathrm{~s}$ to reach the driver, which is $12.5 \%$ delayed compared to winter. When the outside temperature is higher (in autumn, $\mathrm{T}=$ $25^{\circ} \mathrm{C}$, or in summer, $\mathrm{T}=35^{\circ} \mathrm{C}$ ), it takes $5 \mathrm{~s}$ for the droplets to reach the driver, which poses a $25 \%$ delay compared to winter, and $11.1 \%$ delay compared to spring. Results also indicated that the average concentration of droplets at the driver's location in summer is higher than that in autumn.

In addition, droplet diffusion speed depends on temperature. When the outdoor temperature is $5^{\circ} \mathrm{C}$ (in winter), the diffusion speed of droplets is approximately $0.634 \mathrm{~m} \mathrm{~s}^{-1}$. As the temperature increases to $15^{\circ} \mathrm{C}$ (in spring), $25^{\circ} \mathrm{C}$ (in autumn), and $35^{\circ} \mathrm{C}$ (in summer), the droplets' diffusion speed are $0.629 \mathrm{~m} \mathrm{~s}^{-1}, 0.624 \mathrm{~m} \mathrm{~s}^{-1}$, and $0.601 \mathrm{~m} \mathrm{~s}^{-1}$, respectively.

In conclusion, the outside temperature has an influence on the diffusion of the droplets, with higher temperature leading to lower droplet diffusion speed and longer time until the droplets reach the driver. 


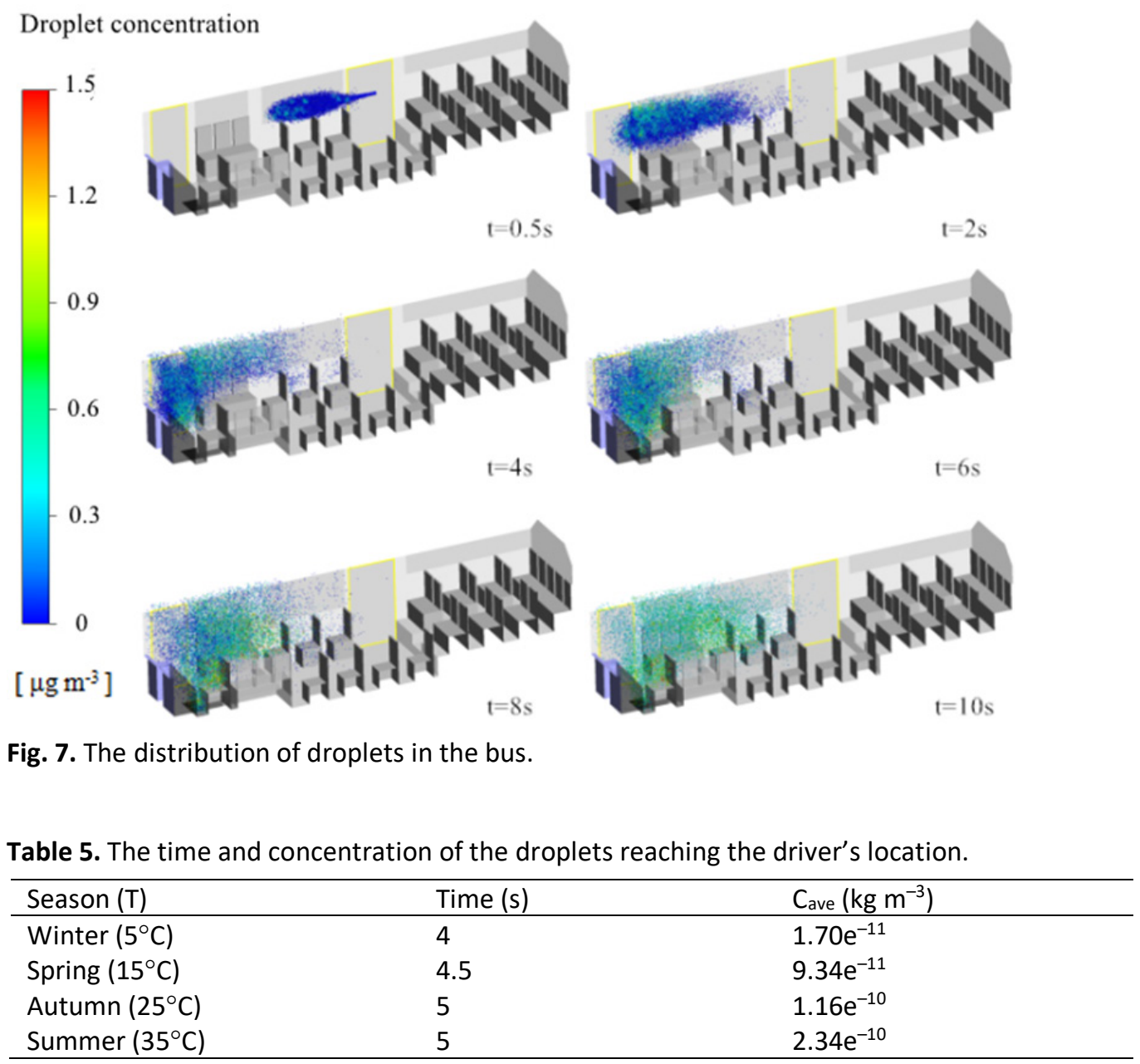

\subsubsection{The distribution of droplets in different seats}

The integral concentration of droplets at different locations in different seasons is also quite different, as shown in Fig. 8. It appears that when the passenger exhales the droplets at position $3 \mathrm{D}$, the integral concentration of droplets at the location of the driver and seats $2 \mathrm{~A}, 2 \mathrm{~B}$, and $2 \mathrm{C}$ are always higher than $0.1 \mu \mathrm{g}$ and $0.025 \mu \mathrm{g}$, respectively, which are significantly higher than at other locations in the bus at $\mathrm{t}=10 \mathrm{~s}$, putting the driver and passengers of these seats at greater risk than other passengers. The higher risk of these locations can be mainly attributed to the small temperature gradient at these locations that allows the droplets to diffuse and suspend in these locations, maintaining their integral concentration high.

With regards to how the driver and passengers are affected, when the outdoor temperature is $25^{\circ} \mathrm{C}$, the integral concentration of droplets around the driver's location is the highest $(0.212 \mu \mathrm{g})$, which is about 1 to 2 times that corresponding to other outdoor temperatures. And except for seats $1 \mathrm{~A}, 1 \mathrm{~B}$, and $1 \mathrm{C}$, the quantitative relationship of the integral concentration of droplets at other seats in the bus at different outdoor temperatures is similar to that of the driver's position. That is, when the outdoor temperature is $25^{\circ} \mathrm{C}$, the integral concentration of droplets in the bus is significantly higher than that at other outdoor temperatures. The difference of seats $1 \mathrm{~A}, 1 \mathrm{~B}$, and $1 \mathrm{C}$ is attributed to their location, close to the front door of the bus, allowing their flow velocity and temperature gradient to change greatly, hence causing the droplet concentration to be different from other positions. This indicates that there may be an optimal temperature for droplet diffusion.

In summary, regardless of season, collectors should be mainly located in seats $2 \mathrm{~A}, 2 \mathrm{~B}, 2 \mathrm{C}, 3 \mathrm{~A}$, $3 \mathrm{~B}, 3 \mathrm{C}$, and the location of the driver to reduce the risk of expanding the situation and reduce the scope of the affected population. Furthermore, as indicated in Fig. 8, the integral concentration of droplets at the location of the driver is significantly higher than that of other positions. 


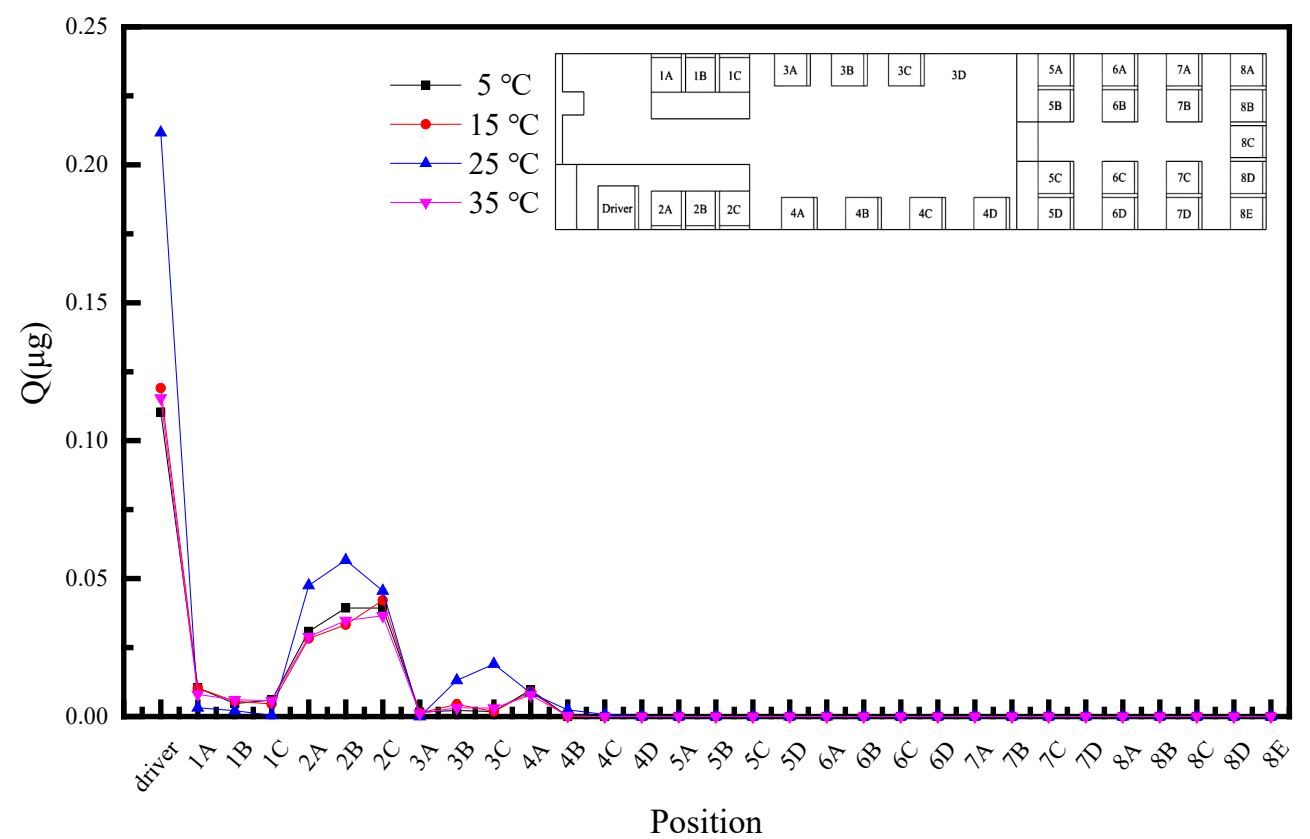

Fig. 8. The integral concentration of droplets at different locations in the bus.

Compared with passengers, the driver spends more time in the bus during a day. Thus, isolation measures should be set up to prevent droplets from spreading to the driver's location. Although various cities in China have set up safety protection facilities around bus drivers, the protection measures can only prevent passengers from physically hurting the drivers, not effectively prevent the spread of droplets. This is because the droplets spread initially from the right side of the driver to the top of the driver's head, and then gradually spread to the driver's location (Fig. 7). As a result, it is necessary to reform the existing safety protection facilities to strengthen the isolation of the upper area of the driver's location, and effectively prevent the spread of droplets to the driver's location to reduce the concentration of droplets in the driver's position, thereby effectively reducing the associated infection risk.

\subsection{Effect of Droplet Exhalation Position on Droplet Diffusion and Distribution}

\subsubsection{Diffusion characteristics of droplets exhaled at different locations}

Undoubtedly, passengers will sit in random locations when boarding the bus. Hence four different exhalation positions were simulated with the outside temperature being set at $35^{\circ} \mathrm{C}$. In scene 1 , a passenger located in seat $2 \mathrm{~B}$ (front of the bus) exhaled droplets. In scene 2, a passenger located in position 3D exhaled droplets. In scene 3, a passenger located in seat $8 \mathrm{C}$ (back of the bus) exhaled droplets. In scene 4, the passengers in all three locations mentioned before exhaled droplets. The diffusion trajectory of droplets in the four different scenarios is presented in Fig. 9.

As can be seen from Fig. 9(a), for scene 1 (passenger located in seat 2B), the droplets released in the bus diffuse to seat $1 \mathrm{~B}$ due to the airflow in this direction, and gather in a conical form at $\mathrm{t}$ $=0.5 \mathrm{~s}$. After that, the droplets gradually spread towards the front of the bus and the center of the bus. In the end, at $t=10 \mathrm{~s}$, the droplets mainly gather in the front space of the bus.

In scene 2 (passenger located in position 3D), the droplets first spread to the front and roof of the bus, before gradually spreading to the driver's location. Then the droplets spread to the space in the middle of the bus, and at $t=10 \mathrm{~s}$, a large amount of droplets are suspended in the front space of the bus, as shown in Fig. 9(b).

In scene 3 (passenger located in seat $8 \mathrm{C}$ ), the droplets move forward first. At $t=4 \mathrm{~s}$, the configuration of droplets presents a " $U$ " shape, as shown in Fig. 9(c). This is because the droplets spread to the air supply opening, and the droplets move downward due to the direction of airflow (Fig. 10). When the droplets move to the return air outlet, they end up moving upward, due to the upward airflow (Fig. 10) before finally escaping. At $t=10 \mathrm{~s}$, the droplets are finally suspended in the carriage in a "T" shape. 
In scene 4, passengers located in all three positions are exhaling droplets simultaneously. As illustrated in Fig. 9(d), the diffusion and distribution of droplets in the bus on this occasion are the superposition of the previously described individual scenes. At $t=10 \mathrm{~s}$, the droplets are fully suspended in the entire compartment.

Based on the aforementioned examination, the diffusion range of droplets is different for different droplet exhalation position. Table 6 indicates the start position and end position of the distribution of droplets in the $X$ direction at $t=10 \mathrm{~s}$, for the different droplet exhalation positions simulated. Results demonstrate that in summer, when only one person exhales droplets, the largest diffusion range is caused by the passenger in seat $8 C$, followed by seat $2 B$, and finally position $3 \mathrm{D}$. This is because seat $8 \mathrm{C}$ is in the last row of the bus, and droplets will continue spreading towards the front of the bus. Seat $2 \mathrm{~B}$ is in the front row of the bus, so droplets will

(a)

\section{Droplet concentration}
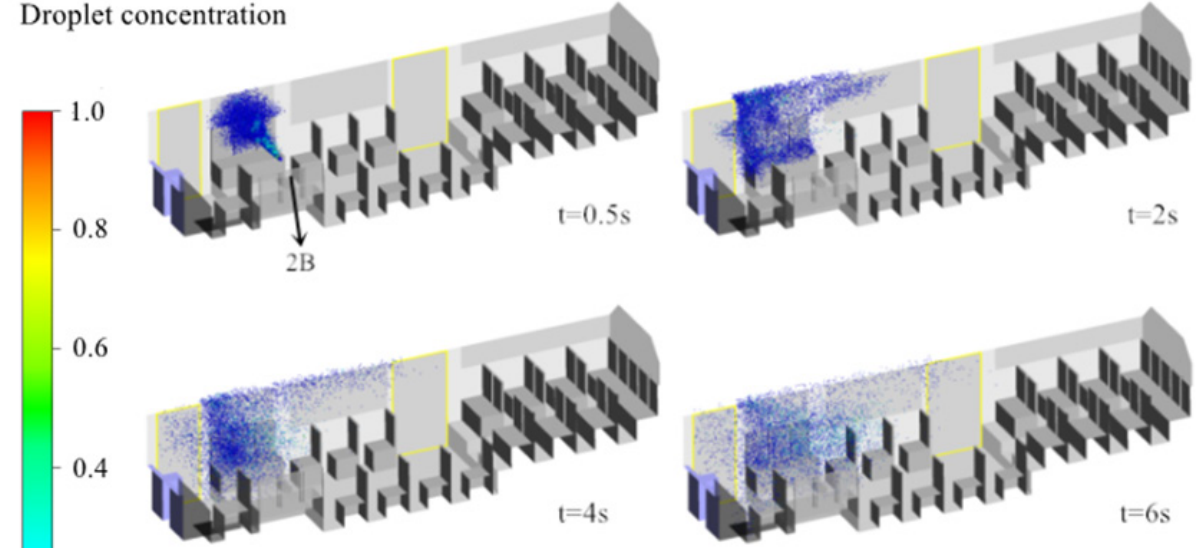

$\underset{0}{0.2}$

$\left[\mu \mathrm{g} \mathrm{m}^{-3}\right]$
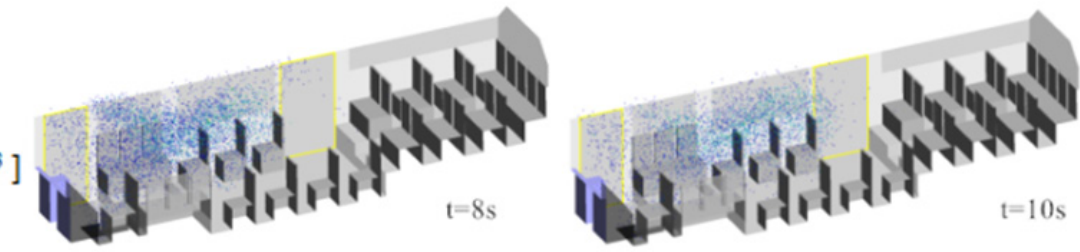

(b) Droplet concentration
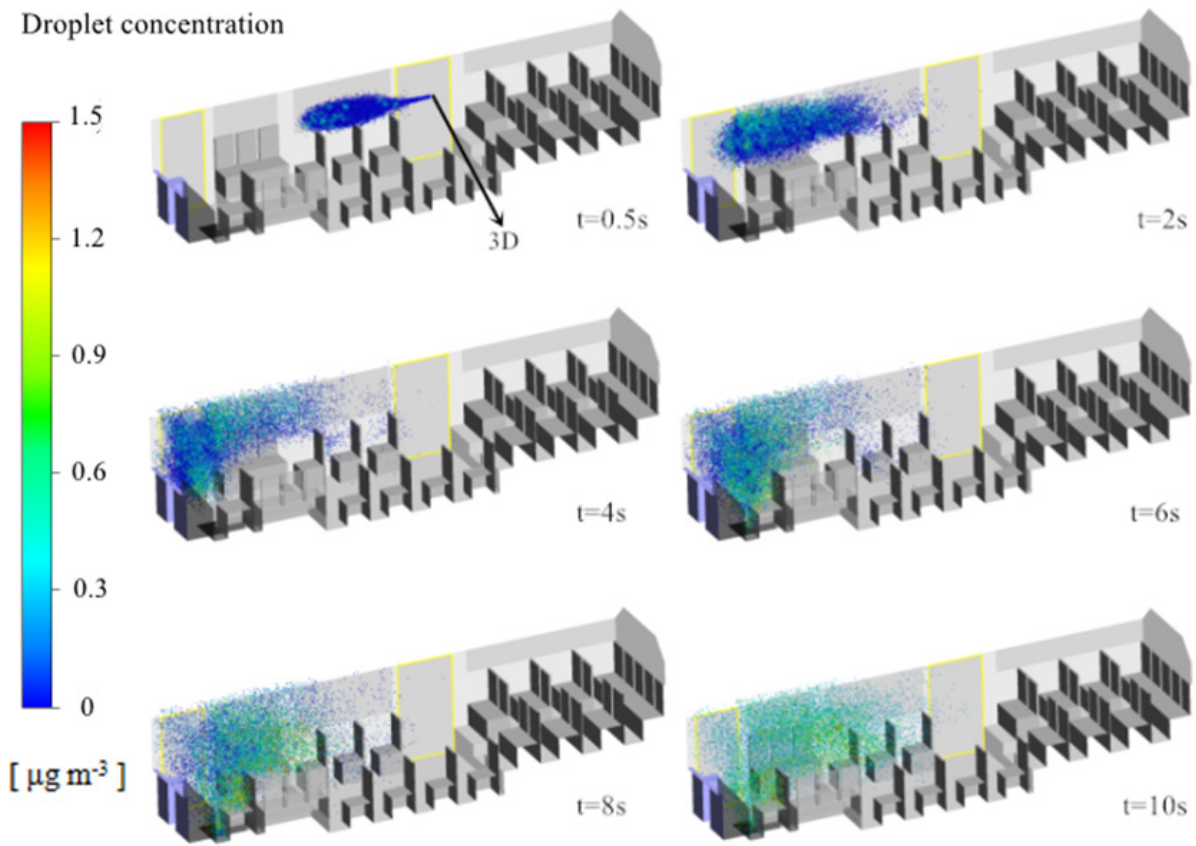

Fig. 9. The diffusion of droplets in the bus (a) scene 1: located at $2 \mathrm{~B}$ position (b) scene 2: located at $3 \mathrm{D}$ position (c) scene 3 : located at $8 \mathrm{C}$ position (d) scene 4 : located at $2 B / 3 D / 8 C$ positions. 
(c)

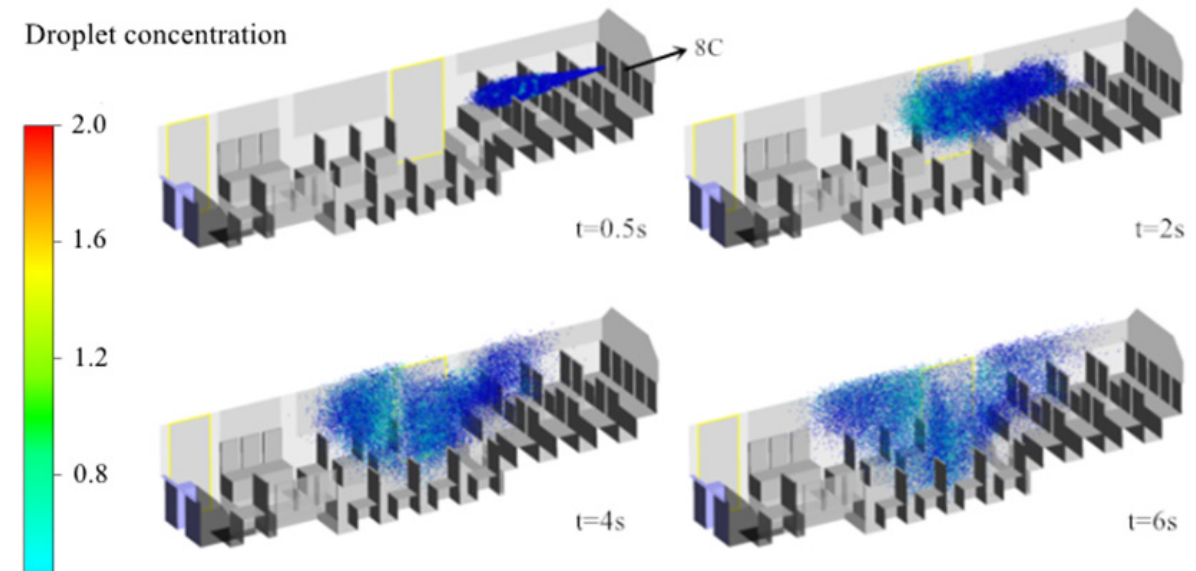

0.4
0

$\left[\mu \mathrm{g} \mathrm{m}^{-3}\right]$
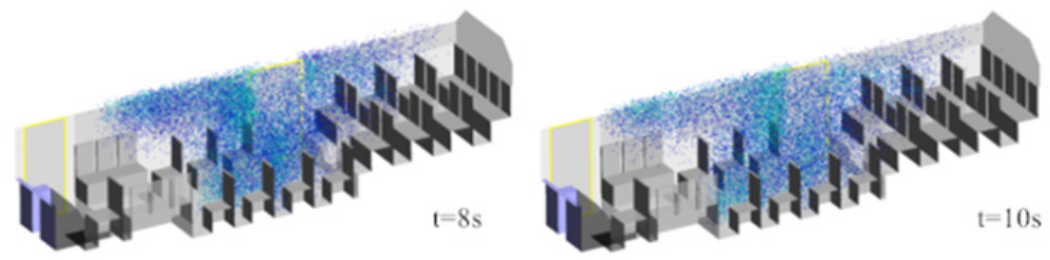

(d)

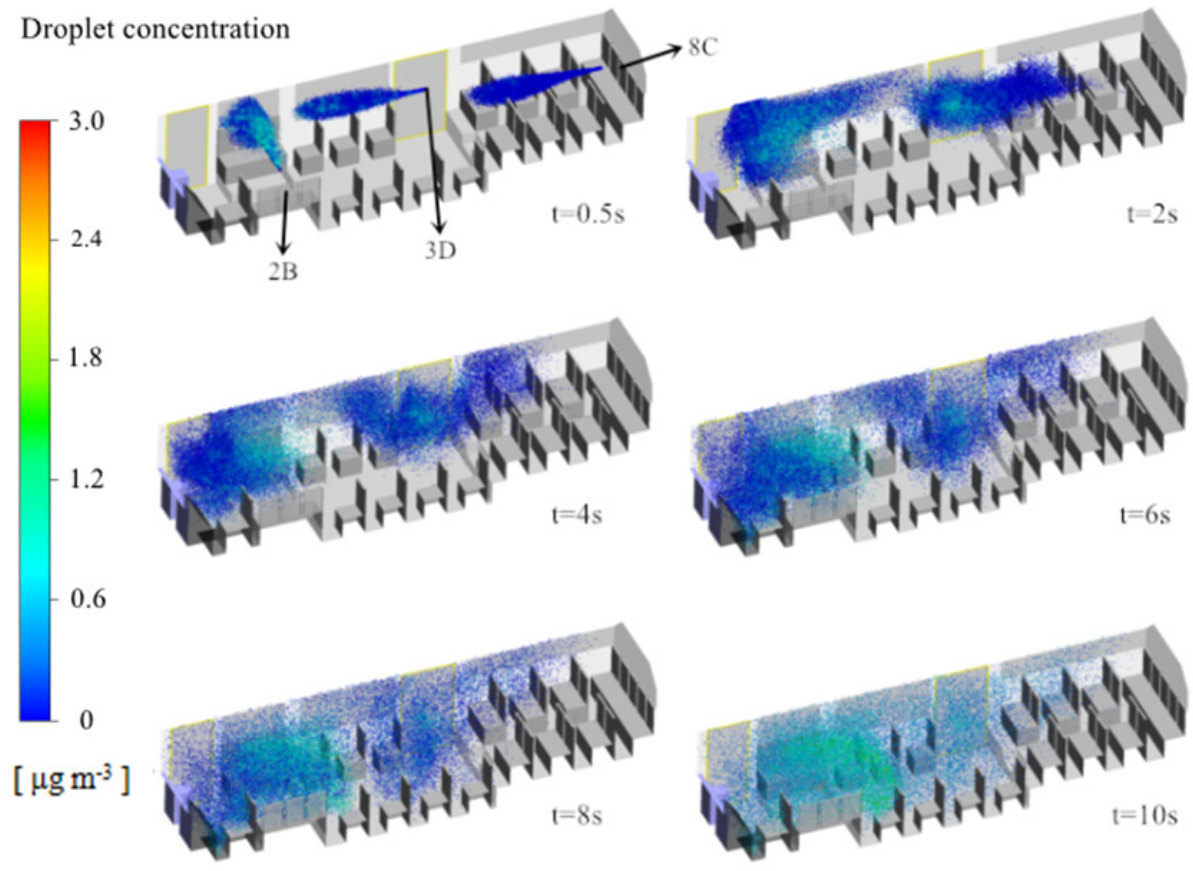

Fig. 9. (continued).

spread to both the front and rear of the bus. However, position 3D is at the back door of the bus, close to the door gap and the return air outlet, so some droplets will escape, thus minimizing the spread. Compared with any individual passenger exhaling droplets, if passengers in all three locations exhale droplets simultaneously, the diffusion range will be the largest, being a superposition of the diffusion ranges of the three individual positions.

\subsubsection{The distribution of droplets in different seats}

Different droplet exhalation positions result in different diffusion ranges, so it is necessary to calculate the integral concentration of droplets of different seats in the bus for the different droplet exhalation scenarios in the bus. Results of this calculation are shown in Fig. 11. As can be seen from Fig. 11, for all four scenarios, there are droplets at seats $1 \mathrm{~A}, 1 \mathrm{~B}, 1 \mathrm{C}, 3 \mathrm{~A}, 3 \mathrm{C}, 4 \mathrm{~A}$ and $4 \mathrm{~B}$. 
Velocity

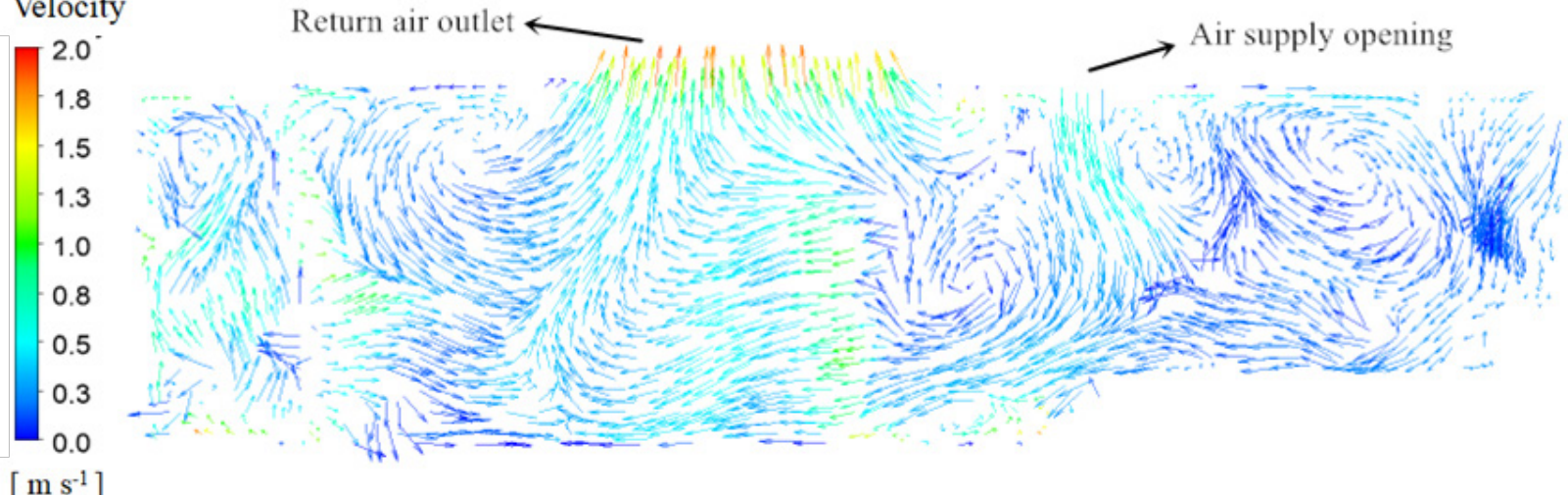

$\left[\mathrm{m} \mathrm{s}^{-1}\right]$

Fig. 10. The speed distribution at $Y=1.15 \mathrm{~m}$.

Table 6. The diffusion range of droplets along $X$ direction.

\begin{tabular}{llll}
\hline Droplet exhalation position & Current simulation $\left(\mu \mathrm{g} \mathrm{kg}^{-1}\right)$ & Zhao et al. $(2005)\left(\mu \mathrm{g} \mathrm{kg}^{-1}\right)$ & Relative error \\
\hline 2B & 0 & 6.509 & 6.509 \\
3D & 0 & 5.443 & 5.443 \\
8C & 1.079 & 9.996 & 8.887 \\
$2 \mathrm{~B} / 3 \mathrm{D} / 8 \mathrm{C}$ & 0 & 9.996 & 9.996 \\
\hline
\end{tabular}

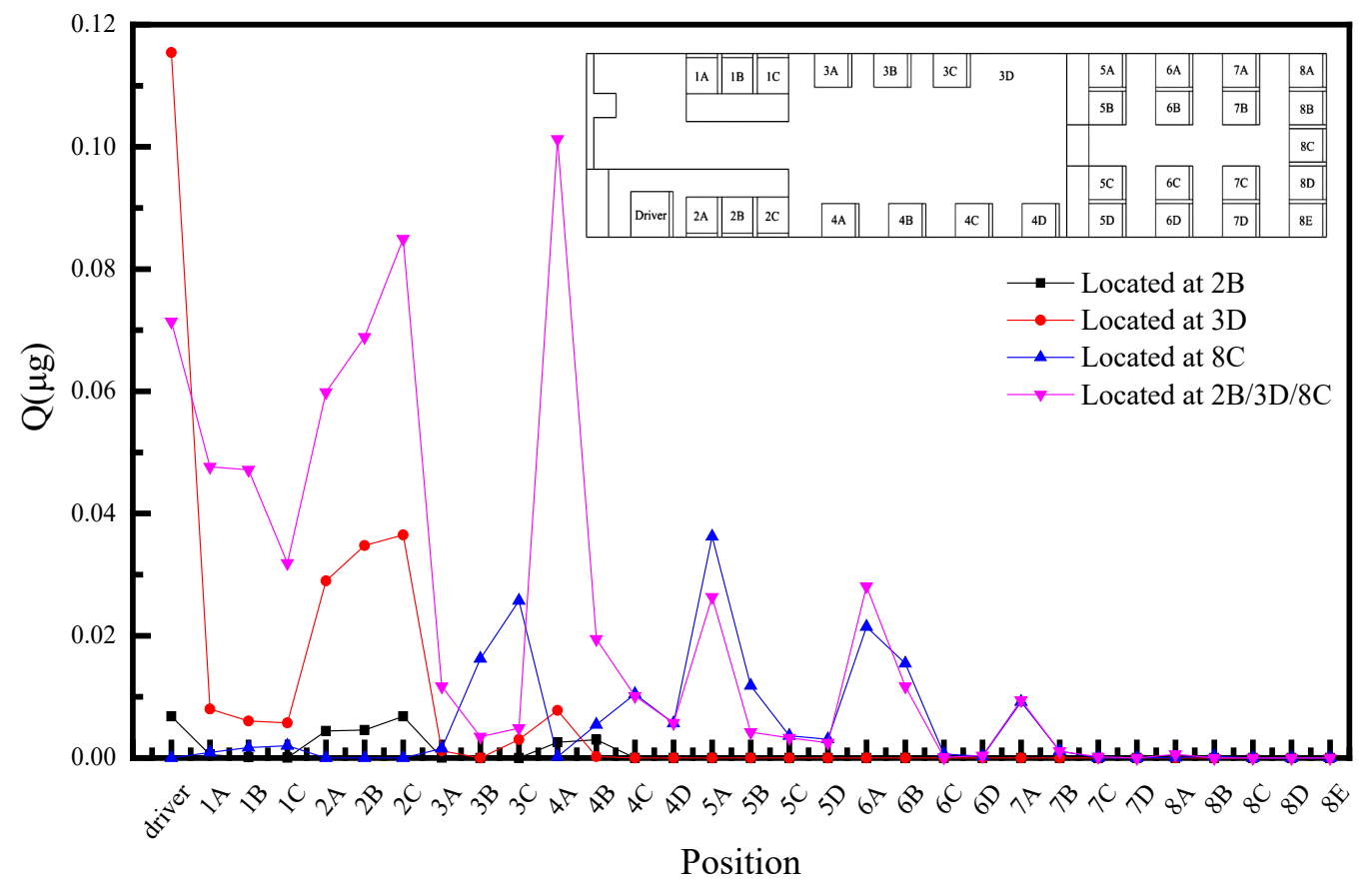

Fig. 11. The integral concentration of droplets in different scenarios.

The integral concentration of droplets is as low as $5.65 \times 10^{-7} \mu \mathrm{g}$ and as high as $0.1013 \mu \mathrm{g}$. Hence, these seats are considered to be less safe and belong to higher risk areas. This is because the seats $1 \mathrm{~A}, 1 \mathrm{~B}, 1 \mathrm{C}$ and $3 \mathrm{C}$ are close to the door, and the air leakage through the gap of the door makes the droplets gradually spread to these positions. The seats $3 \mathrm{~A}, 4 \mathrm{~A}$, and $4 \mathrm{~B}$ are in the middle of the bus, so no matter where the droplets are exhaled, there will be a spread towards that direction. On the contrary, seats $8 \mathrm{C}, 8 \mathrm{D}$, and $8 \mathrm{E}$ are in the back row of the bus, far away from the door and the air vent. Besides, the air flow in these locations is small, so the integral concentration of droplets detected is $0 \mu \mathrm{g}$, categorizing these seats to the area with lower risk. 
Another observation of Fig. 11 also shows that when a passenger exhales droplets at position $3 \mathrm{D}$, the integral concentration of droplets at the driver's location is approximately $0.1154 \mu \mathrm{g}$, which is about 17 times that of droplets exhaled by a passenger in seat $2 \mathrm{~B}$. Furthermore, whether the passenger exhales droplets at position $3 D$ or seat $2 B$, the integral concentration of droplets at the driver's position is significantly higher than at other locations in the bus. The reason is that when the droplets spread towards the front door of the bus, the droplets will spread to the driver due to the airflow by the door gap, which leads to higher integral concentration of droplets at the driver's location compared to other passengers in the bus in both these scenarios. However, when the passenger exhales droplets at seat $8 \mathrm{C}$, most of the droplets are suspended in the upper area of the bus and do not spread to the driver's location, with results showing no droplets at the driver's location in this scenario.

In summary, the risk of passengers on the bus is related to the location of the passenger who exhaled the droplets. When the passenger exhales droplets at seat 2B or position 3D in the bus, the rear of the bus is considered a low-risk area. On this occasion, the front seats, especially the driver's location, show a higher integral concentration of droplets. However, when a passenger exhales droplets in seat $8 \mathrm{C}$ in the bus, the droplets will spread toward the door, and when passing through the air supply opening, the droplets will move toward the ground. When the droplets pass through the return air outlet, the droplets will move upward and then escape from the bus. On this occasion, only the driver, passengers on the driver's side $(2 \mathrm{~A}, 2 \mathrm{~B}, 2 \mathrm{C})$, and some passengers in the back row $(7 C, 7 D, 8 C, 8 D, 8 E)$ are the lower risk areas.

\section{CONCLUSIONS}

Obvious characteristics of a bus are the large passenger flow and closed space, with the enclosed environments in the bus making the infection risk of respiratory diseases higher due to droplet diffusion. A numerical model based on a practical case was established to analyze the effect of the outdoor temperature and the exhalation position on the diffusion of droplets in the bus. Four outdoor temperatures $\left(5^{\circ} \mathrm{C}, 15^{\circ} \mathrm{C}, 25^{\circ} \mathrm{C}, 35^{\circ} \mathrm{C}\right)$ and four exhalation positions are considered in the study. The integral concentration of different seats in the bus is calculated and summarized to determine low-risk areas and high-risk areas in the bus. The conclusions are as follows:

(1) The outside temperature has an influence on the diffusion of droplets, with higher temperature leading to lower diffusion speed of the droplets and longer time until they reach the driver. In winter (external temperature assumed at $5^{\circ} \mathrm{C}$ ), it takes 4 seconds for the droplets to reach the driver's location from being exhaled. In summer (external temperature assumed at $35^{\circ} \mathrm{C}$ ), it takes 5 seconds for the droplets to reach the driver, which implying a $25 \%$ delay compared to winter.

(2) When a passenger exhales droplets at position 3D in the bus, the integral concentration of droplets at the driver's location is highest in autumn, which is about 1 to 2 times that of other seasons. And when the outdoor temperature is $25^{\circ} \mathrm{C}$, the integral concentration of droplets in the bus is significantly higher than that at other outdoor temperatures, with the exception of seats $1 \mathrm{~A}, 1 \mathrm{~B}$, and $1 \mathrm{C}$. This indicates that there may be an optimal temperature for droplet diffusion.

(3) In summer, when only one passenger is responsible for droplet exhalation, the exhalation position with the largest impact range is seat $8 \mathrm{C}$, followed by seat $2 \mathrm{~B}$, and finally position $3 \mathrm{D}$. Compared with only one passenger exhaling droplets, if passengers in all three positions exhale droplets, the impact range is the largest, due to the superposition of the diffusion range for each of the three positions.

(4) The difference in the location of the passengers exhaling droplets leads to differences in the integral concentration of droplets at different seats in the bus. For the driver, the integral concentration of droplets reaching the driver when exhaled by a passenger in position 3D is about 17 times that of droplets' concentration reaching the driver when a passenger in seat 2B exhales.

(5) In order to reduce the spread of infectious disease viruses during respiratory infections, in addition to setting up collectors in buses, passengers can also protect themselves from droplet transmission by sitting on seats in the low-risk area. Furthermore, the safety protection facility 
around the driver should be modified to improve the isolation of the upper area of the driver's location, so as to effectively prevent the spread of droplets to the driver's location, thereby effectively reducing the driver's risk.

\section{ACKNOWLEDGMENTS}

The study is supported by Hubei Technological Innovation Special Fund (Grant Nos. 2020ZYYD019) and Undergraduate Innovation Research Program (S202010488016).

\section{REFERENCES}

Ai, Z.T., Huang, T., Melikov, A.K. (2019). Airborne transmission of exhaled droplet nuclei betweenoccupants in a room with horizontal air distribution. Build. Environ. 163, 106328. https://doi.org/10.1016/j.buildenv.2019.106328

Ansys Inc. (2018). ANSYS Help.

Bartzis, J.G., Efthimiou, G.C., Andronopoulos, S. (2015). Modelling short term individual exposure from airborne hazardous releases in urban environments. J. Hazard. Mater. 300, 182-188. https://doi.org/10.1016/j.jhazmat.2015.06.057

Berlanga, F.A., Olmedo, I., Adana, M.R.D. (2017). Experimental analysis of the air velocity and contaminant dispersion of human exhalation flows. Indoor Air 27, 803-815. https://doi.org/10. 1111/ina.12357

Berlanga, F.A., Olmedo, I., Adana, M.R.D., Villafruela, J.M., José J.F. San, Castro, F. (2018). Experimental assessment of different mixing air ventilation systems on ventilation performance and exposure to exhaled contaminants in hospital rooms. Energy Build. 177, 207-219. https://doi.org/10.1016/j.enbuild.2018.07.053

Cao, G., Nielsen, P.V., Jensen, R.L., Heiselberg, P., Liu, L., Heikkinen, J. (2015). Protected zone ventilation and reduced personal exposure to airborne cross-infection. Indoor Air 25, 307-319. https://doi.org/10.1111/ina.12142

Chen, C., Zhao, B. (2010). Some questions on dispersion of human exhaled droplets inventilation room: Answers from numerical investigation. Indoor Air 20, 95-111. https://doi.org/10.1111/j. 1600-0668.2009.00626.x

Chen, W., Zhang, N., Wei, J., Yen, H., Li, Y. (2020). Short-range airborne route dominates exposure of respiratory infection during close contact. Build. Environ. 176, 106859. https://doi.org/10.1 101/2020.03.16.20037291

Gralton, J., Tovey, E., Mclaws, M.L., Rawlinson, W.D. (2011). The role of particle size in aerosolised pathogen transmission: A review. J. Infect. 62, 1-13. https://doi.org/10.1016/j.jinf.2010.11.010

He, Q., Niu, J., Gao, N., Zhu, T., Wu, J. (2011). CFD study of exhaled droplet transmission between occupants under different ventilation strategies in a typical office room. Build. Environ. 46, 397-408. https://doi.org/10.1016/j.buildenv.2010.08.003

Ji, Y., Qian, H., Ye, J., Zheng, X. (2018). The impact of ambient humidity on the evaporation and dispersion of exhaled breathing droplets: A numerical investigation. J. Aerosol. Sci. 115, 164172. https://doi.org/10.1016/j.jaerosci.2017.10.009

Lateb, M., Masson, C., Stathopoulos, T., Bédard, C. (2013). Comparison of various types of k-ع models for pollutant emissions around a two-building configuration. J. Wind Eng. Ind. Aerodyn. 115, 9-21. https://doi.org/10.1016/j.jweia.2013.01.001

Li, X., Niu, J., Gao, N. (2014). Spatial distribution of human respiratory droplet residuals and exposure risk for the co-occupant under different ventilation methods. HVAC\&R RES. 17, 432445. http://dx.doi.org/10.1080/10789669.2011.57869

Licina, D., Melikov, A., Pantelic, J., Sekhar, C., Tham, K.W. (2015). Human convection flow in spaces with and without ventilation: Personal exposure to floor-released particles and coughreleased droplets. Indoor Air 25, 672-682. https://doi.org/10.1111/ina.12177

Lindsley, W.G., Blachere, F.M., Thewlis, R.E., Vishnu, A., Davis, K.A., Cao, G., Palmer, J.E., Clark, K.E., Fisher, M.A., Khakoo, R., Beezhold, D.H. (2010). Measurements of airborne influenza virus in aerosol particles from human coughs. Plos One. 5, e15100. https://doi.org/10.1371/journal. pone.0015100 
Liu, L., Li, Y., Nielsen, P.V., Wei, J., Jensen, R.L. (2016). Short-range airborne transmission of expiratory droplets between two people. Indoor Air 27, 452-462. https://doi.org/10.1111/ina. 12314

Liu, L., Wei, J., Li, Y., Ooi, A. (2017). Evaporation and dispersion of respiratory droplets from coughing. Indoor Air 27, 179-190. https://doi.org/10.1111/ina.12297

Liu, P., Zhang, H., Li, D. (2016). Dynamic characteristics of human droplet indoor transmission. Refrig. Air Conditioning. 30, 371-376. https://doi.org/10.3969/j.issn.1671-6612.2016.04.001 (in Chinese)

Mao, J., Gao, N. (2015). The airborne transmission of infection between flats in high-rise residential buildings: A review. Build. Environ. 94, 516-531. https://doi.org/10.1016/j.builden v.2015.09.026

Mcgrath, J.A., O’Sullivan, A., Bennett, G., O’Toole, C., Joyce, M., Byrne, M.A., MacLoughlin, R. (2019). Investigation of the quantity of exhaled aerosols released into the environment during nebulisation. Pharmaceutics. 11, 75. https://doi.org/10.3390/pharmaceutics 11020075

Mui, K.W., Wong, L.T., Wu, C.L., Lai, A.C.K. (2009). Numerical modeling of exhaled droplet nuclei dispersion and mixing in indoor environments. J. Hazard. Mater. 167, 736-744. https://doi.org/10.1016/j.jhazmat.2009.01.041

National Bureau of Statistics (2020). China Statistical Yearbook 2020. http://www.stats.go v.cn/tjsj/ndsj/2020/indexch.htm

National Health Commission of the People's Republic of China (2020). https://voice.baid u.com/act/newpneumonia/newpneumonia/?from=osari_aladin_banner

Patanker, S.V., Spalding, D.B. (1972). A calculation processure for heat, mass and momentum transfer in three-dimensional parabolic flows. Int. J. Heat Mass Transfer 15, 1787-1806. https://doi.org/10.1016/0017-9310(72)90054-3

Prata, D.N., Rodrigues, W., Bermejo, P.H. (2020). Temperature significantly changes COVID-19 transmission in (sub) tropical cities of Brazil. Sci. Total Environ. 729, 138862. https://doi.org/1 0.1016/j.scitotenv.2020.138862

Qian, H., Li, Y., Seto, W.H., Ching, P., Ching, W.H., Sun, H.Q. (2010). Natural ventilation for reducing airborne infection in hospitals. Build. Environ. 45, 559-565. https://doi.org/10.1016/ j.buildenv.2009.07.011

Rahman, H.S., Aziz, M.S., Hussein, R.H., Othman, H.H., Salih Omer, S.H., Khalid, E.S., Abdulrahman, N.A., Amin, K., Abdullah, R. (2020). The transmission modes and sources of COVID-19: A systematic review. Int. J. Surg. Open. 26, 125-136. https://doi.org/10.1016/j.ijso.2020.08.017

Shih, T.H., Liou, W.W., Shabbir, A., Yang, Z., Zhu, Y. (1995). A new k-ع eddy viscosity model for high reynolds number turbulent flows. Comput. Fluids. 24, 227-238. https://doi.org/10.1016/ 0045-7930(94)00032-T

Stilianakis, N.I., Drossinos, Y. (2010). Dynamics of infectious disease transmission by inhalable respiratory droplets. J. R. Soc. Interface. 7, 1355-1366. https://doi.org/10.1098/rsif.2010.0026

Vuorinen, V., Aarnio, M., Alava, M., Alopaeus, V., Atanasova, N., Auvinen, M., Balasubramanian, N., Bordbar, H., Erästö, P., Grande, R., Hayward, N., Hellsten, A., Hostikka, S., Hokkanen, J., Kaario, O., Karvinen, A., Kivistö, I., Korhonen, M., Kosonen, R., ..., Österberg, M. (2020). Modelling aerosol transport and virus exposure with numerical simulations in relation to SARSCoV-2 transmission by inhalation indoors. Saf. Sci. 130, 104866. https://doi.org/10.1016/j.ssc i.2020.104866

Wang, M., Jiang, A., Gong, L., Lu, L., Guo, W., Li, Chuyi, Zheng, J., Li, Chaoyong, Yang, B., Zeng, J., Chen, Y., Zheng, K., Li, H. (2020). Temperature significantly change COVID-19 transmission in 429 cities. medRxiv 2020.02.22.20025791. https://doi.org/10.1101/2020.02.22.20025791

World Health Organization (WHO) (2020). Disease outbreaks. https://www.who.int/emerg encies/diseases/en/

Xie, X., Li, Y., Chwang, A.T.Y., Ho, P.L., Seto, W.H. (2007). How far droplets can move in indoor environments-revisiting the Wells evaporation-falling curve. Indoor Air 17, 211-225. https://doi.org/10.1111/j.1600-0668.2007.00469.x

Xu, C., Wei, X., Liu, L., Su, L., Liu, W., Wang, Y., Nielsen, P.V. (2020). Effects of personalized ventilation interventions on airborne infection risk and transmission between occupants. Build. Environ. 180, 107008. https://doi.org/10.1016/j.buildenv.2020.107008

Yan, Y., Li, X., Tu, J. (2019). Thermal effect of human body on cough droplets evaporation and 
dispersion in an enclosed space. Build. Environ. 148, 96-106. https://doi.org/10.1016/j.builde nv.2018.10.039

Yang, C., Yang, X., Zhao, B. (2014). Person to person droplets transmission characteristics in unidirectional ventilated protective isolation room: The impact of initial droplet size. Build. Simul. 9, 597-606. https://doi.org/10.1007/s12273-016-0290-7

Yang, C., Yang, X., Zhao, B. (2015). The ventilation needed to control thermal plume and particle dispersion from manikins in a unidirectional ventilated protective isolation room. Build. Simul. 8, 551-565. https://doi.org/10.1007/s12273-014-0227-6

Yang, X., Ou, C., Yang, H., Liu, L., Song, T., Kang, M., Lin, H., Hang, J. (2020). Transmission of pathogen-laden expiratory droplets in a coach bus. J. Hazard. Mater. 397, 122609. https://doi.org/10.1016/j.jhazmat.2020.122609

Zhang, L., Li, Y. (2012). Dispersion of coughed droplets in a fully-occupied high-speed rail cabin. Build. Environ. 47, 58-66. https://doi.org/10.1016/j.buildenv.2011.03.015

Zhang, Y., Feng, G., Bi, Y., Cai, Y., Zhang, Z., Cao, G. (2019). Distribution of droplet aerosols generated by mouth coughing and nose breathing in an air-conditioned room. Sust. Cities Soc. 51, 101721. https://doi.org/10.1016/j.scs.2019.101721

Zhao, B., Zhang, Z., Li, X. (2003). Numerical study of indoor human body droplet transmission. HVAC. https://doi.org/CNKI:SUN:NTKT.0.2003-03-051

Zhao, B., Zhang, Y., Li, X., Yang, X., Huang, D. (2004). Comparison of indoor aerosol particle concentration and deposition in different ventilated rooms by numerical method. Build. Environ. 39, 1-8. https://doi.org/10.1016/j.buildenv.2003.08.002

Zhao, B., Wu, J. (2005). Numerical investigation of particle diffusion in a clean room. Indoor Built Environ. 14, 469-479. https://doi.org/10.1177/1420326X05060190

Zhao, B., Zhang, Z., Li, X. (2005). Numerical study of the transport of droplets or particles generated by respiratory system indoors. Build. Environ. 40, 1032-1039. https://doi.org/10.10 16/j.buildenv.2004.09.018

Zhou, J., Wei, J., Choy, K.T., Sia, S.F., Rowlands, D.K., Yu, D., Wu, C.Y., Lindsley, W.G., Cowling, B.J., McDevitt, J., Peiris, M., Li, Y., Yen, H.L. (2018). Defining the sizes of airborne particles that mediate influenza transmission in ferrets. PNAS 115, E2386-E2392. https://doi.org/10.1073/p nas.1716771115

Zhou, Q., Qian, H., Ren, H., Li, Y., Nielsen, P.V. (2017). The lock-up phenomenon of exhaled flow in a stable thermally-stratified indoor environment. Build. Environ. 116, 246-256. https://doi.org/10.1016/j.buildenv.2017.02.010

Zhu, S., Kato, S., Yang, J.H. (2006). Study on transport characteristics of saliva droplets produced by coughing in a calm indoor environment. Build. Environ. 41, 1691-1702. https://doi.org/10.1 016/j.buildenv.2005.06.024

Zhu, S., Srebric, J., Spengler, J.D., Demokritou, P. (2012). An advanced numerical model for the assessment of airborne transmission of influenza in bus microenvironments. Build. Environ. 47, 67-75. https://doi.org/10.1016/j.buildenv.2011.05.003 